use of labyrinthine signs and symptoms in the differential diagnosis of allied labyrinthine affections is very carefully worked out. It is to be noted that the fact is emphasised that, in diffuse labyrinthine suppuration, the radical operation alone-without at the same time opening and draining the labyrinth-actually adds to the danger of intracranial infection.

In suspected lateral sinus thrombosis, Kerrison is opposed to opening the sinus unless there is very definite evidence of the presence of a clot. He confesses, however, that this view will not have the support of many distinguished aural surgeons. Aspiration movements of the sinus are, he has found, very suggestive of the presence of a thrombus.

The chapters dealing with aural operations are satisfactory. In operating for acute mastoiditis he does not consider it advisable to take too much pains to secure a smooth bone cavity; too great smoothness, he believes, interferes with the formation of granulations. In the radical mastoid operation he does not favour primary skin-grafting.

Valuable chapters are those on the use of salvarsan and vaccines in the treatment of aural disease. With regard to the former, the author gives its indications, with statisties dealing with the frequency of cranial nerve lesions following its use. He considers the leucocyte extract of His to be of decided value in selected cases.

Although there is little that is original or entirely new in Dr. Kerrison's text-book, it is valuable from the fact that it brings into line most of the latest work upon its subject, and, as such, it should prove of great use to students and practitioners of otology.

Macleod Yearsley.

\title{
NOTES AND QUERIES.
}

" It would be interesting to learn how far the linguistic peculiarities of a race are moulded by its susceptibility to colds in the head.

"The pronunciation of the gutturals and sibilants of the Teuton and Sclav is unaffected by the circumstance that the speaker may be suffering from nasal eatarrh.

"The melodious tones of Italy, Spain and many other Celtic nations can only be produced by generations of men accustomed to inhabit lands where the air is soft and warm, and conducive to indolence rather than to obstruction of the nose."From "How to Avoid Colds : By One who does" (Anon).

\section{Salicylate of Iron for Acutr Tonsillitis and Erysipelas.}

M. C. S. Lawrence speaks highly of this drug in the diseases mentioned. He has found it abort the development of the latter. The dose is 3 to 10 grains, every three hours. - Practitioner, March, 1913, p. 633.

It gives us great pleasure to intimate that Prof. Killian, of Berlin, has been unanimously elected Semon Lecturer in Laryngology of the University of London for 1914, and that he has accepted the nomination. The Lecture will be delivered towards the end of May.

We have mueh pleasure in informing our readers that Prof. Killian has been elected, by the Verein Deutscher Laryngologen, President of the next International Congress of Laryngology, to be held in Hamburg in 1915 contemporaneously with the International Congress of Otology under the presidency of Prof. Denker.

\section{Thr Cure of Deafness by Radidy.}

"Retzius" asks : "Can you or your readers inform me as to whether any further evidence has come to hand as to the utility of radium in deafness? A reply under the following heads would be much valued:

"(1) Nature of aural disease in which it is most likely to prove useful.

"(2) Dose, method of application, and frequency and duration of séances." 


\section{HOSPITAL FOR \\ DISEASES OF THE THROAT, GOLDEN SQUARE, LONDON, W.}

HONORARY MEDICAL STAFF.

Consulting Surgeons $\left\{\begin{array}{l}\text { MR. MARK HOVELL. } \\ \text { DR. LAMBERT LACK. }\end{array}\right.$

Surgeons.

DR. J. W. BOND ...

Mr. CHARLES PARKER ...

DR. FITZGERALD POWELL

Mr. FRANK ROSE ... ...

Mr. JEFFERSON FAULDER

Mr. GEORGE BADGEROW

Assistant SuRgeons.

Mr. NORMAN PATTERSON

Mr. CHARLES HOPE ...

Mr. LIONEL COLLEDGE ..

Dental Surgeon.

DR. J. W. PARE
Out.Patients.

... Wednesday, 2.0 P.M.

.. Tuesday, 2.0 P.M.

Friday, 2.0 P.M.

... Monday, 2.0 P.M.

... Thursday, 2.0 P.M.

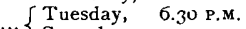

*. Saturday; 2.0 P.M.

$\cdots\left\{\begin{array}{l}\text { Monday, } \\ \text { Friday, }\end{array}\right.$

Attendances.

Monday, 9.0 A.M., Tuesday, 2.0 P.M., Friday, 2.0 P.м. Tuesday, 6.30 P.M., Wednesday, 2.0 P.M., Saturday, 2.0 P.M. Monday, 2.0 P.M., Thursday, 2.0 P.M., Friday, 6.30 P.м.

Thursday, 9.30 A.M.

\begin{abstract}
Operations.
F. Friday, IO.I5 A.M. … $\}$ Wednesday, 10.0 A.M.

... Thursday, I0.0 A.M.

... Friday, 2.0 P.M.

‥ Tuesday, $\quad 9.30$ A.M.

...

9.0 A.M.
\end{abstract}

\section{CLINICAL INSTRUCTION.}

A Clinical Demonstration on the Diagnosis and Treatment of Selected Cases (Larynx, Nose, Ear) will be given each Monday at $5.3 \circ$ p.m.

A Course in Surgical Anatomy and Physiology will be given each Thursday at 5.30 p.m. Tinese Courses are free to Students of the Hospital. Others a fee of 2 guineas for each Course.

Practical Instruction in the Diagnosis and Treatment is given daily in the Out-patient Department from 2 to 5 p.m., on Tuesdays and Fridays from $6.3^{\circ} \mathrm{p} . \mathrm{m}$. to 9 p.m., and Mondays at 9.30 a.m.

Major Operations are performed at ro a.m. on Tuesday, Wednesday, Thursday, Friday, and Saturday, and Fridays at 2 p.m.

Minor Operations daily (Mondays excepted) at 9.30 a.m.

Operative Surgery Classes can be formed at any time on application.

Practice in Direct Laryngoscopy, Tracheoscopy, Bronchoscopy, and Esophagoscopy will be given to Students, to enable them to become familiar with the use and manipulation of the instruments.

Practitioners and Medical Students are admitted to the Practice of the Hospital at a fee of five guineas for three months, eight guineas for six months, or ten guineas for a Perpetual Studentship. Each course may commence at any date. Special terms to men in actual practice who can only attend the hospital once or twice a week.

The Hospital contains 48 beds for In-patients. There is also an Out-patient attendance of nearly 50,000 yeariy.

Gentlemen may enter to the practice of The Throat Hospital at any time, and on certain conditions eligible for appointment as Clinical Assistants, whose duty it is to Assist the Member of the Staff to whom they are appointed.

GEORGE W. BADGEROW, F.R.C.S., Hon. Med. Sec. 


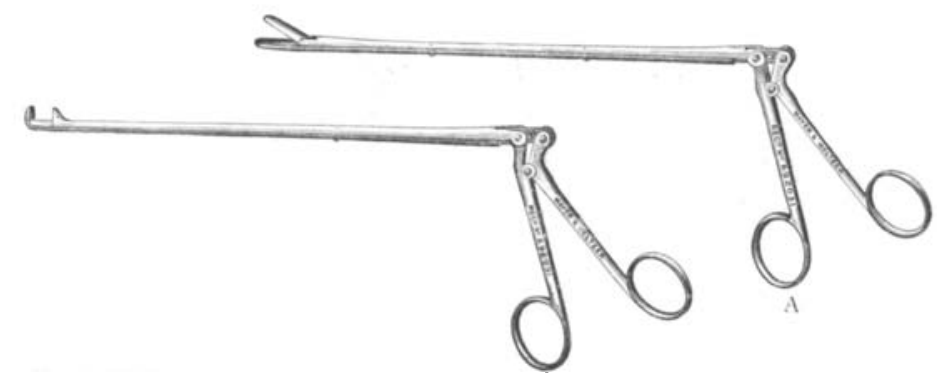

DAN McKENZIE'S

B

\section{Improved DIRECT ACTION NIBBLING FORCEPS,}

With improved joint, which obviates all " kick" when closing the forceps. Absolutely steady in use. ("Emandem" Registered Design.)
A. Straight pattern
$\cdots$
$\ldots \quad \& 1176$
B. Rectangular for anterior commissure
$\ldots \begin{array}{cccc}2 & 2 & 17 & 6 \\ & 2 & 0 & 0\end{array}$

\section{Improved Aseptic Guillotine.}

Designed by HUGH JONES, M.R.C.S., L.R.C.P.

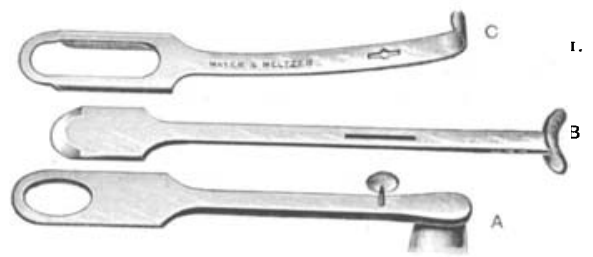

Advantages.

I. The instrument consists of thret parts only-

A. The bed or lower plate to which the handle and turn button are fixed and of which they form part.

B. The blade.

C. The spring upper sheath.

There are no screws or other small fittings which are liable to be lost.

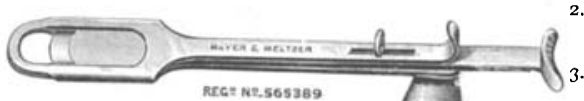

2. The handle is a fixture and cannot turn or become loose at a critical moment.

3. The upper sheath being removable, all parts of the instrument are accessible for cleaning.

4. The spring sheath exerts pressure on the blade at just the right point to ensure its accurately fitting the bed plate and so cutting efficiently.

5. The shape of the handle and the angle at which it is set, combined with the diminished length of the instrument, give greatly increased leverage, making it possible to entirely enucleate a tonsil if the Made in 3 sizes, each 25/\%. proper size guillotine is selected.

\section{MAYER \& MELTZER, 7I, GT. PORTLAND STREET, LONDON.}

Branches : MELBOURNE; CAPETOWN; JOHANNESBURG. 


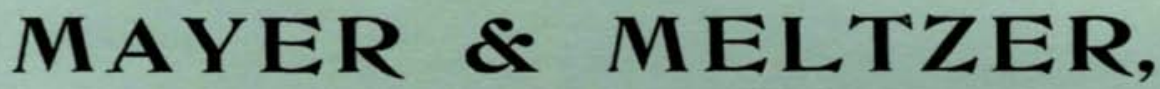

Surgical Instrument Makers.

1863

ESTABLISHED 50 YEARS

1913

\section{Instrument to Facilitate Per=Oral Bronchoscopy.}

Devised by WiLt.uM Hut., M.D., and shown at the May Meeting of the Laryngological Section of the Royal Society of Medicine.

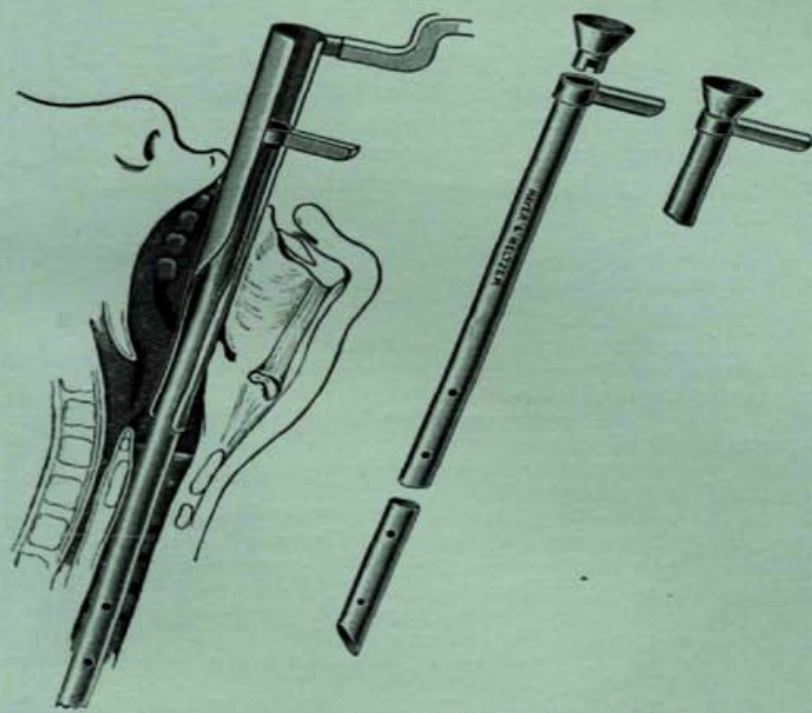

The lateral slot not only permits of binocular vision and easy instrumentation when operating on the larynx, but it also facilitates the rapid passage of a tracheoscope or broncho. seope in cases where (1) there is dyspnosa from spasm, ete., during operations on the larynx, more especially in children; (2) for per-oral tracheobronchoscopic explorations where there is difficulty or delay in finding the contracted laryngeal vestibule, more especially when working with a narrow bronchoscope alone in children; (3) to relieve at once, without resorting to tracheotomy, the temporary spasmodic dyspnoca which sometimes supervenes on administering an anresthetic in cases of laryngeal and tracheal obstruction.

Full particulars of Dr. William Hill's Esophagoscopic Instrument and of the Gastroscope will be found in

Cur New : Laryngology-Rhinology-Otology containing upwards of $\mathbf{1 7 0 0}$ illustrations, just published. If you have not received a copy it is due to an oversight, which will be promptly remedied on receipt of a postcard.

MAYER \& MELTZER, 7I, GREAT PORTLAND ST., LONDON.

Branches: MELBOURNE; CAPETOWN; JOHANNESBURG. 


\section{The "Allenburys" \\ (мabrataro) Throat Pastilles \\ Efficient

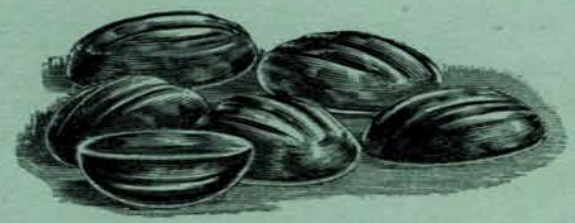 \\ Palatable}

The basis of the "Allenburys" Throat Pastilles is a special pâte de jujube. The pastilles are demulcent, soluble and palatable, and contain accurate amounts of pure active drugs. They dissolve slowly and uniformly, so ensuring the thorough suffusion of the mucous membrane, and the prolonged continuous direct effect of the active ingredients.

The following pastilles are largely used, and have been found from long practical experience to be very efficacious.

No. 9. Menthol, Cocaine and Red Gum

No. 23. Eucalyptus and Red Gum

No. 28. Compound Guaiacum

No. 29. Compound Rhatany

No. 38. Chlorate of Potash, Borax and Cocaine

No. 75. Formaldehyde and Menthol

No. 77. Formaldehyde and Cinnamon Oil

Formaldehyde, min. 1: Ol. Cinnamon, min. t

1/- box of any variety, with detailed list, free to Medical Men in Great Britain.

IMPORTANT.-To ensure the supply of these active and reliable medicinal products, medical men should designate the

"ALLENBURYS" Pastilles in their prescriptions.

Allen \& Hanburys Itd. London

NIAGARA FALLS, N.Y.

TORONTO

BUENOS AIRES.

DURBAN.

SYDNEY. 